\title{
Eating Behavior after Experimentally Induced Emotions
}

\author{
Laessle $\mathrm{R}^{\star}$ and Kertz $\mathrm{H}$ \\ Department of Biological and Clinical Psychology, University of Trier, Trier, Germany \\ *Corresponding author: Laessle R, Department of Biological and Clinical Psychology, University of Trier, \\ 54286 Trier, Germany, Tel: +49 (0)651/201-2009, E-mail: laessle@uni-trier.de
}

Citation: Laessle R, Kertz H (2018) Eating Behavior after Experimentally Induced Emotions. J Obes Overweig 4(1): 104. doi: $10.15744 / 2455-7633.4 .104$

Received Date: February 13, 2018 Accepted Date: May 26, 2018 Published Date: May 28, 2018

\begin{abstract}
Based on theoretical considerations which hypothesize a significant influence of emotions on eating behavior a laboratory experiment was conducted. 127 subjects of both sexes were investigated after the induction of joy or sadness with subsequent presentation of chocolate. Neither gender nor the quality of the emotion had a significant effect on the consumed amount of chocolate, but habitual dietary restraint of the subjects lead to lower intake of the sweet food. The results are discussed with respect to the usefulness of a cognitive control of eating behavior in successful treatment programs for obesity.
\end{abstract}

Keywords: Emotions; Eating behavior

\section{Introduction}

Emotions are thought to serve distinct motivational functions and to contribute essentially to the control of behavior. Specific emotions such as anger, fear, sadness, and joy, as well as moods have been found to affect eating behavior along the entire process of ingestion. Emotions can increase food intake in one group of persons, e.g. restrained eaters, but decrease intake in another group, e.g non-restrained eaters. Furthermore, different emotions may increase or decrease eating in the same group of individuals. For example, boredom can be associated with increased appetite, but sadness with decreased appetite. Obesity, in particular in women, has been hypothesized to be related to the fact that women are more sensitive to eat sweets in negative mood [1]. Eating behavior in response to negative affect has also been shown to be significantly influenced by the degree of cognitive control of food intake that means dietary restraint. Dietary restraint describes the intention of individuals to restrict their food intake in order to lose weight or to prevent weight gain. Restrained eaters cognitively instead of physiologically control their eating behavior under normal circumstances. The behavioral strategies involve for example deliberately limiting one's food intake per day, calculating consumed energy, avoiding high calorie dishes, ending a meal before reaching satiety, and frequent weighing. The present investigation was designed to test the influence of positive and negative emotions on the ingestion of sweet food (chocolate) in men and women. Dietary restraint was hypothesized to be a significant moderating factor.

\section{Method}

127 (91 female) subjects aged between 18 and 35 years and of normal body weight were recruited for an investigation to test the taste of chocolate when in different mood. The degree of dietary restraint was assessed by the German version of the Three Factor Eating Questionnaire (factor "cognitive control of eating") [2]. Subjects completed the questionnaire after they had finished the taste test. Two excerpts from popular movies were used to induce emotions. A sequence from "The champ" to induce sadness (boy cries at the death of his father, 2:51 min). A sequence from "When Harry met Sally" to induce joy (a woman and a man have a discussion about orgasms, 2:35 min). Both film clips had already been found to induce the aimed emotions successfully [3]. In the present investigation emotion ratings of sadness and joy, respectively, increased significantly from before seeing the film clip to after seeing the film clip. The sequence of the presentation of the film clips was randomized. For the taste test pieces of chocolate (whole milk, 10g) were presented in a container which was weighed before and after induction of emotions. Before starting the experiment, it was assured for all subjects that they liked chocolate, from which they could taste and eat as much as they wanted.

\section{Statistical analysis}

A regression analysis was performed. As the dependent variable the amount of consumed chocolate was used. The predictive variables were Sex (male/female), emotion quality (sadness, joy), and the degree of dietary restraint, that had been assessed by the Three Factor Eating Questionnaire. 


\section{Results}

Table 1 shows the descriptive statistics for the variables which were included in the regression analysis

\begin{tabular}{|c|c|c|}
\hline & & t-Test \\
\hline $\begin{array}{c}\text { Female } \\
\text { Male }\end{array}$ & $\begin{array}{c}15.1 \pm 9.0 \\
17.6 \pm 12.7\end{array}$ & ns \\
\hline $\begin{array}{c}\text { Joy } \\
\text { Sadness }\end{array}$ & $\begin{array}{l}16.0 \pm 10.5 \\
15.6 \pm 10.0\end{array}$ & ns \\
\hline $\begin{array}{l}\text { Low restraint } \\
\text { High restraint }\end{array}$ & $\begin{array}{c}17.7 \pm 11.6 \\
13.6 \pm 7.7\end{array}$ & $\mathrm{p}<.02$ \\
\hline
\end{tabular}

Table 1: Means and SD for consumed chocolate in variables included in regression analysis

Females and males did not differ in chocolate consumption after induction of emotions. The emotion induction itself also did not lead to significant differences in chocolate consumption, but significant mean differences in consumption were observed between subjects with a high or low restraint score.

Table 2 presents the coefficients, obtained in the regression equation.

\begin{tabular}{|c|c|c|c|}
\hline Variable in regression & $\begin{array}{c}\text { Simple } \\
\text { correlation }\end{array}$ & $\begin{array}{c}\text { Regression coef- } \\
\text { ficient (Beta) }\end{array}$ & $\begin{array}{c}\text { Significance level } \\
\text { (two-tailed) }\end{array}$ \\
\hline Sex & .11 & .07 & $\mathrm{~ns}$ \\
\hline Emotion & -.02 & -.01 & $\mathrm{~ns}$ \\
\hline Dietary restraint & -.27 & -.26 & .004 \\
\hline
\end{tabular}

Table 2: Results of regression analysis; Dependent variable: consumed chocolate after emotion induction

The regression equation was significant $\mathrm{F}(3,121)=3.5, \mathrm{p}<.02$, but neither sex nor the quality of emotions contributed significantly to explain variance in chocolate consumption. Only the effect of dietary restraint was significant with a higher degree predicting lower intake of chocolate.

\section{Discussion}

The results of the present experiment are somewhat contradictory to previous studies that have found significant effects of negative emotions on eating behavior and motivation to eat [3,4]. In a similar study of Bongers et al. [4] effects of emotions on sweet food (chocolate mousse) have been found. They used a pavlovian conditioning paradigm and comparable film clips to trigger different moods, but the participants were substantially longer exposed to the sad mood, which could explain their positive results and the lack of effects by the short term exposure in our study.

It was also not confirmed that negative mood particularly enhances the preference to consume sweets as had been found in [5].

Instead we found that the degree of dietary restraint was the only significant predictor of chocolate consumption after triggering positive and negative emotions, independent from gender and quality of the emotion. The higher the degree of dietary restraint was the lower was the amount of consumed chocolate. The ability of cognitive control of food intake therefore seems to be a protecting factor against overconsumption of sweets, although a person is in negative mood. This interpretation is empirically supported by studies evaluating successful treatment programs for obesity [6].

Our results are supported by a recent study of Tan and Holub [7] in young children, who were in short term sadness and consumed more chocolate than during joy. This could be explained because of the children being too young for an adequate cognitive control for eating sweets.

Not only short term mood swings are associated with chocolate consumption but also longer-lasting negative mood which is present in depressive disorders. This has been found in the study of Rose et al. [8], and may result in overweight, if there is no ability for cognitive control of food intake, especially for sweets.

There are several limitations that have to be considered when interpreting the results. The sample size was small and requires replication with more subjects and a broader age range. Only two emotions have been induced. Whether the results would hold also when testing other states, e.g. anger vs calmness may be questioned.

\section{Conclusion}

The consumption of sweet food after exposure to negative emotions is dependent on a person's general ability for cognitive control of food intake. This ability is also needed for successful weight reduction in treatment programs for obese patients. 


\section{Compliance with Ethical Standards}

Informed consent was obtained from all individual participants included in the study.

\section{Acknowledgment}

The Bachelor students P. Soballa, M. Boenig, F. Kieser, J. Kravcikova, P. Krischer, S. Leinweber, J. Nikolaus, C. Richter, M. Sand, L. Schebitz, L. Schwindt, L. Steichen assisted in data collection.

\section{References}

1. Slowchower J (1983) Excessive eating: The role of emotions and environment. New York: Human Sciences Press, USA.

2. Pudel V, Westenhöfer J (1989) The questionnaire on eating behavior (FEV) [Der Fragebogen zum Eßverhalten (FEV)], Hogrefe, Göttingen, Germany.

3. Macht M, Roth S, Ellgring H (2002) Chocolate eating in healthy men during experimentally induced sadness and joy. Appetite 39: 147-58.

4. Bongers P, van den Akker K, Havermans R, Jansen A (2015) Emotional eating and Pavlovian learning: does negative mood facilitate appetitive conditioning? Appetite 89: 226-36.

5. Oliver G, Wardle J (1999) Perceived effects of stress on food choice. Physiol Behav 66: 511-5.

6. Allison DB, Pi-Sunyer FX (1995) Characteristics of successful weight loss maintainers In: Obesity Treatment: Establishing Goals, Improving Outcomes, and Reviewing the Research Agenda. New York, Plenum Press, USA.

7. Tan CC, Holub SC (2018) The effects of happiness and sadness on Children's snack consumption. Appetite 123: 169-74.

8. Rose N, Koperski S, Golomb BA (2010) Mood food: chocolate and depressive symptoms in a cross-sectional analysis. Arch Intern Med 170: 699-703.

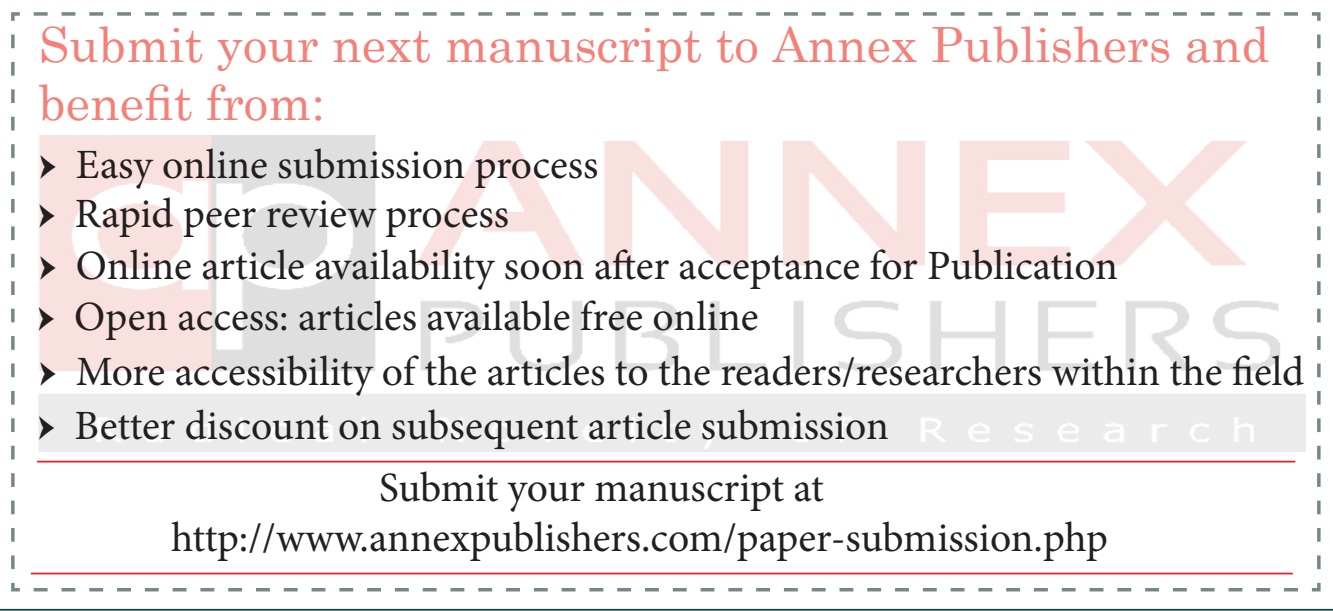

